\title{
Frustacionit and Crime in Contemporary Society - Case Study the Western Balkan
}

\author{
Fatmir Qollkaj, PhD.c. \\ Pro-Dean of the of University Law, \\ Lector University AAB - Deanery-Law, Pristina
}

Abstract

\begin{abstract}
When we talk about society, in particular in terms of developing its sociological us always remains good impression when talking to a healthy society and developed, however long history of social development gives us to understand that the development of society is also followed by numerous pathological phenomenon, deviant and criminal. This phenomenon, as the development of regression contradictions are development testified as a driving force of society, not just the dialectical point of view worldly but also from the standpoint of Merton Dyrkemit of other thinkers of the twentieth century. Criminality as a result of the promoters, different forces the drive has been the phenomenon of early and ongoing follow-up of human society, caused in most of the time the frustrations such as individual and collective. Starting from the individual, then the family, group and to greater social organization, frustrations are manifest modalities of development as controversial complex, multidimensional social. Changes occurring in contemporary society in the late twentieth century terms as in terms development economic, technical and technological followed with profound changes in the political, legal and cultural. These changes greatly influenced the lives of states social training, companies involved in this global development where ragging result of increased individual and collective result of which is also the growing crime in intensity and modalities manifest.
\end{abstract}

Keywords: Frustacionit, Crime in Contemporary Society, Western Balkan

\section{Introduction}

Frustration as emotion, as the state is inevitable feature as at the individual level as well as collectively, throughout the history of development of human society, each time with increased intensity of times the intensity of the smallest forms less stable. "The situationragging caused, bullied by a cause, by not achieving the fulfillment of physical or spiritual needs of man, and these may be different as poverty, violence, not essential success, and many other differentreasonwe encounter in life our daily.Experiencing this emotion in people is different as is the expression of various complaints raised also, if we take as an example of "poverty" is undoubtedly a factor that became frustrated highest percentage of people worldwide depending on degree what is this hardshipraggingrate is as large, long lifeeveryone encountered such a situation due to lack of fulfillment of the need materialistic. However important is how to achieve to become a solution to the problem through methods that are accepted by society and these methods do not illegal.It is positive ifragging acts as incentive to achieve the good life purposes such as education, business, etc.But on the other hand when he combined with criminal offenses areundoubtedly considerable damage.

\section{Collective Frustacionit}

Collective frustrations show discrepancies situation (distance) between the reception and achieving fulfillment of needs, goals of a social group within a society, or society itself as' total. When it comes to organized society in the state and collective frustrations can add that changes occurred in the political and social life in the last threeyears the twentieth century in a part of Europe and in particular in the Western Balkans had to follow a corporate ragging (thanks absolute majority) resulting re influenced by social stratification and social training realignment in life.Changes in policy have been changes in the economy, social training and general life created a new system axiological with essential major differences based on value, with a new system of qualified freely. Unequivocally that these changes are driven and caused a collective ragging which manifested with different intensities to different individuals in major addiction by many factors such as personality of the individual, family, culture, subcultures his economic situation etc."This collectiveragging manifested as aggression, as" grumbling "through illegal actions until they are extreme, criminal actions. " (Haskoviq Mujo, Psychology).

So the Western Balkans converted to the appropriate field and extent of crime in all its forms, especially the modalities of drug crime, trafficking in human beings, murder, rape etc. What makes the particular Western Balkans in the context for 
which we refer to is the escalation of collective rabies and modify its collective aggression.As was said collective rage succeeds as configuration and spontaneous accumulation of collective energy high intensity based on the increasing dissatisfaction as the result of not meeting and not meeting the objectives of large, high collective national interest.The better example is the situation in the former Yugoslavia in the early 90 -ties beginning of the breakup of the former federal state, then the other example is the overthrow of the dictatorship and neodictatorship in Albania, since 97 where the death toll was over 3000 people.

FRUSTACIONIT collective results as a collective response to fear because in modern societies is today "We live in such a time and culture where it seems only basic sense of collective fear" (Sofradjija \& Agjalic Kriminalisticke Topic Sarajevo 2011)

\section{Individual Frustacionit}

Frustrated man is the man who fails to fulfill his motives because of the severe obstacle that can not own it.Such situations are a source of frustration to the man and his experience, which is caused by such situation there are specific nature and special performances. "Man is man desperate frustrated, anxious, fearful, withdrawn and upset, that overtakes an interior concern seriously.Such experiencing strong influences on the intellectual processes in everyday life and in the person's behavior toward others and to ourselves of his own.. "(Nushi Pajazit, General Psychology).

To others frustrated man appeared a kind of disorder was warm contacts and Disorder Act of pace, contacts with others. To himself that his special behavior; begins to think deeply about its nature overtakes even this thought for a long time. The manragging show some physiological changes, associated with life change his feelings. However frustrated people react differently to their condition ragging. Howeverraggingpeople react differently to their condition ragging .Some triple their activity to possess obstacle or frustrating situation, others reorganize behavior, actions and their wishes to come down to the lowest level of aspirations, changing the purpose of fulfilling specific theme, changing ways of performing the theme and utilizing new tools for achieving the pursued.

"Failure to resolve personal and family issues or other issuesthrough the legal existence creates opportunities and opens the path for other forms of action which often end with diverse passions and victims' (Ragip Halili, ,Victimolog, Pristina 2011)

Separate form of manifestation ofragging is wandering, embracing characteristic of a subculture and ignoring the normalization life. "This category of persons deriving from families where drugs consumed, poor families where none of the parents does not work, problematic families" (Zejneli Ismail, delinquency of minors in the Republic of Macedonia 2008 )

\section{Various forms of criminality as a Result of Frustacionit}

Criminality is one of the biggest risks in the system stabilized ethical norms and social values. Criminality is a major economic burden for the community (detection, apprehension, trial, punishment, rehabilitation of the criminal). "Another reason for the curiosity of the 'ordinary man' 'for criminality is knowledge of street-life personality and the person who has committed any criminal act, and that again is a function of better understanding the behavior of people and the actions their in general. "(HaskoviqMujo, Forensic Psychology).

No matter from which aspect we want to know criminality in any social community, first ask the question how widespread this phenomenon.Answer on this question first of all give us different criminal statistics, where the structure of offenses within a year dominationraggingoffenses caused by an individual, where offenses have passionate primates ( 5 murders of love, rejection of love, jealousy, inability the unity and common life data made public by Electronic media coverage, Tirana, Albania, cases decided by life imprisonment).

As a result of frustration and aggression we can conclude that a lot of criminal acts can be committed for money reasons such as property thefts, (a criminal act that is growing rapidly) as well as other criminal acts such as murderers, violations, etc. "Apart from the social environment, the perpetrator's personality as a unique notion is to be considers when we need to analyze the motives of the crime...in the criminalistic practice the most frequent motives pertaining to the commitment of a criminal act are bad economy, hatred, sexual reasons, religious extremism, love, etc". ( Korajlic\&Muharremi , Kriminalistika 2009) 
As mentioned above, political and economic changes and disorders as complex processes in the West Balkans have influenced in the increase of collective frustration which in turn have resulted in the flourishing of the organized crime especially in human trafficking where the majority of victims are juvenile and young girls. "Trafficking of human beings, especially that involving young women as victims of prostitution increases any time there are socio-economic problems and disorders. Such situations are created after great political transformations, during and after political turmoil, civil wars, local wars, recessions and great economic crises. Usually, victims of human trafficking are females of different ages...the findings from IOM for Kosovo in 2000 indicate that the average age of victims is 22 years old”. (GashiRexhep ,Krimi i Organizuar , 2014).

\section{Conclusions}

Finally, we can add that the frustration should be accepted as a psycho-social phenomenon intertwined with elements and characteristics of the personality dependent on the social environment as well as other factors which together fuel criminal acts. Criminality, as a growing phenomenon, deserves an institutional attention in order to prevent it. Additionally, civil society must exert sophisticated control through socialization projects for special social categories which will in turn help the general socialization of the society. The implementation of the punishing policies within a given country as well as the role of the international organizations and international community in general is not to be underestimated.

\section{Literature}

[1] Antony Gidens, Sociology, Tirana 2007

[2] Bakic Ibrahim, Sociology, Sarajevo 1998

[3] RecepGashi, Organized Crime, Pristina, 2014

[4] HaskovicMujo, Forensic Psychology, booklet, Prishtina, 2008

[5] HaskovicMujo, Psychology, scripts in English Pristine 2006

[6] HaskovicMujo, Izbeglistvo of devijantnoponasanje

[7] RagipHalili, Victimology, Pristina 2011

[8] RagipHalili, Criminology, Pristine 2013

[9] KorajlicNedjat\& Muharram Bruno,, Pristine 2009

[10] NushiPajazit, Psychology,, Pristina, 2012

[11] MladjenovicRajk, Criminology Sarajevo 1997

[12] Terry F. Pettijohn, Psychology edition Classifieds, Tirana 1996

[13] Sofradjija\&AgjalicKriminalisticke Topic 2011

[14] VeselLatifi, Criminology Pristine 2014

[15] Zejneli Ismail, delinquency of minors in the Republic of Macedonia in 2008 